\title{
Prolonged survival in patients with breast cancer and a history of brain metastases: results of a preplanned subgroup analysis from the randomized phase III BEACON trial
}

\author{
Javier Cortés ${ }^{1} \cdot$ Hope S. Rugo ${ }^{2} \cdot$ Ahmad Awada $^{3} \cdot$ Chris Twelves $^{4}$. \\ Edith A. Perez ${ }^{5}$ - Seock-Ah Im ${ }^{6}$ Patricia Gómez-Pardo ${ }^{7}$ • Lee S. Schwartzberg 8 . \\ Veronique Diéras ${ }^{9}$ Denise A. Yardley ${ }^{10}$ - David A. Potter ${ }^{11} \cdot$ Audrey Mailliez $^{12}$. \\ Alvaro Moreno-Aspitia ${ }^{1} \cdot$ Jin-Seok Ahn $^{13}$. Carol Zhao ${ }^{14} \cdot$ Ute Hoch $^{14}$. \\ Mary Tagliaferri $^{14}$ • Alison L. Hannah ${ }^{15} \cdot$ Joyce O'Shaughnessy $^{16}$
}

Received: 12 May 2017/ Accepted: 16 May 2017/Published online: 13 June 2017

(c) The Author(s) 2017. This article is an open access publication

\begin{abstract}
Purpose Conventional chemotherapy has limited activity in patients with breast cancer and brain metastases (BCBM). Etirinotecan pegol (EP), a novel long-acting topoisomerase-1 inhibitor, was designed using advanced polymer technology to preferentially accumulate in tumor tissue including brain metastases, providing sustained cytotoxic SN38 levels.

Methods The phase 3 BEACON trial enrolled 852 women with heavily pretreated locally recurrent or metastatic breast cancer between 2011 and 2013. BEACON compared EP with treatment of physician's choice (TPC; eribulin, vinorelbine, gemcitabine, nab-paclitaxel, paclitaxel, ixabepilone, or docetaxel) in patients previously treated with anthracycline, taxane, and capecitabine, including
\end{abstract}

Electronic supplementary material The online version of this article (doi:10.1007/s10549-017-4304-7) contains supplementary material, which is available to authorized users.

Joyce O'Shaughnessy

joyce.oshaughnessy@usoncology.com

1 Ramon y Cajal University Hospital, Madrid, Spain, and Vall d'Hebron Institute of Oncology (VHIO), Barcelona, Spain

2 University of California, San Francisco, CA, USA

3 Medical Oncology Clinic, Jules Bordet Institute, Brussels, Belgium

4 Leeds Institute of Cancer and Pathology and St James's University Hospital, Leeds, UK

5 Mayo Clinic, Jacksonville, FL, USA

6 Seoul National University Hospital, Cancer Research Institute, Seoul National University College of Medicine, Seoul, Korea

7 Vall d'Hebron Institute of Oncology, Barcelona, Spain those with treated, stable brain metastases. The primary endpoint, overall survival (OS), was assessed in a pre-defined subgroup of BCBM patients; an exploratory post hoc analysis adjusting for the diagnosis-specific graded prognostic assessment (GPA) index was also conducted.

Results In the trial, 67 BCBM patients were randomized (EP, $n=36$; TPC, $n=31$ ). Treatment subgroups were balanced for baseline characteristics and GPA indices. EP was associated with a significant reduction in the risk of death (HR $0.51 ; P<0.01$ ) versus TPC; median OS was 10.0 and 4.8 months, respectively. Improvement in OS was observed in both poorer and better GPA prognostic groups. Survival rates at 12 months were $44.4 \%$ for EP versus $19.4 \%$ for TPC. Consistent with the overall BEACON population, fewer patients on EP experienced grade $\geq 3$ toxicity (50 vs. $70 \%$ ).

Conclusions The significant improvement in survival in $\mathrm{BCBM}$ patients provides encouraging data for EP in this

\footnotetext{
The West Clinic, Memphis, TN, USA

Institut Curie, Paris, France

10 Sarah Cannon Research Institute, Nashville, TN, USA

11 Department of Medicine, Masonic Cancer Center, University of Minnesota, Minneapolis, MN, USA

12 Centre Oscar Lambret, Lille, France

3 Department of Medicine, Samsung Medical Center, Sungkyunkwan University School of Medicine, Seoul, Korea

14 Nektar Therapeutics, San Francisco, CA, USA

15 Consultant, Sebastopol, CA, USA

16 Texas Oncology-Baylor Charles A. Sammons Cancer Center/ U.S. Oncology, 3410 Worth Street, Suite 400, Dallas, TX 75246, USA
} 
difficult-to-treat subgroup of patients. A phase three trial of $\mathrm{EP}$ in BCBM patients is underway (ClinicalTrials.gov NCT02915744).

Keywords Brain metastases - Etirinotecan pegol - NKTR$102 \cdot$ Chemotherapy $\cdot$ Metastatic breast cancer

$\begin{array}{ll}\text { Abbreviations } \\ \text { AE } & \text { Adverse events } \\ \text { BC } & \text { Breast cancer } \\ \text { BCBM } & \text { Breast cancer and brain metastases } \\ \text { BEACON } & \text { BrEAst cancer outcomes with NKTR-102 } \\ \text { BM } & \text { Brain metastases } \\ \text { BMH } & \text { History of treated, stable breast cancer brain } \\ & \text { metastases } \\ \text { CI } & \text { Confidence interval } \\ \text { CNS } & \text { Central nervous system } \\ \text { CTCAE } & \text { Common toxicity criteria for adverse events, } \\ & \text { version 4.0 } \\ \text { ECOG } & \text { Eastern Cooperative Oncology Group } \\ \text { EP } & \text { Etirinotecan pegol } \\ \text { ER } & \text { Estrogen receptor } \\ \text { GBM } & \text { Glioblastoma multiforme } \\ \text { GPA } & \text { Graded prognostic assessment } \\ \text { HER2 } & \text { Human epidermal growth factor receptor 2 } \\ \text { HR } & \text { Hazard ratio } \\ \text { ITT } & \text { Intention-to-treat } \\ \text { KM } & \text { Kaplan-Meier } \\ \text { KPS } & \text { Karnofsky performance score } \\ \text { LR } & \text { Locally recurrent } \\ \text { MBC } & \text { Metastatic breast cancer } \\ \text { MMRM } & \text { Repeated measure linear mixed model } \\ \text { NCI } & \text { National Cancer Institute } \\ \text { ORR } & \text { Objective response rate } \\ \text { OS } & \text { Overall survival } \\ \text { PD } & \text { Progressive disease } \\ \text { PFS } & \text { Progression-free survival } \\ \text { PR } & \text { Progesterone receptor } \\ \text { PS } & \text { Performance status } \\ \text { RECIST } & \text { Response evaluation criteria in solid tumors } \\ \text { RT } & \text { Radiation therapy } \\ \text { TPC } & \text { Treatment of physician's choice } \\ & \end{array}$

\section{Introduction}

The rising incidence of brain metastases $(\mathrm{BM})$ as a late manifestation of advanced malignancies is a major clinical problem [1-8], with a prevalence in unselected patients with metastatic breast cancer (MBC) reaching as high as 30\% [2]. Depending on the breast cancer subtype, the vast majority of patients who develop BM have synchronous extra-cranial disease; consequently, effective therapeutic strategies must control intra-cranial and extracranial disease while maintaining or improving patients' quality of life (QoL) [7, 8]. Indeed, in patients with breast cancer and $\mathrm{BM}$ (BCBM), control of systemic disease is strongly associated with improved outcomes [9-11]. Treatment options for patients with BCBM, whether de novo, recurrent following prior local surgery and/or radiotherapy, or progressive disease on radiotherapy are dismal, with small prospective trials showing modest response rates and short palliative benefit $[5,11-15]$.

No cytotoxic or molecularly targeted agent is approved for the treatment or prevention of BCBM [11, 12]. Molecular weight, lipophilicity, biodistribution, and drug efflux pumps all contribute to poor penetration of drugs through the blood-brain barrier and into the brain [16], although extent to which therapeutic resistance relates to inadequate drug penetration remains unclear, as does the degree to which the blood-tumor barrier is disrupted $[11,12,15]$. Current therapies have limited activity in patients with BCBM, especially those recurring post-radiation therapy $[5,11-14,17]$. This is particularly important for patients with triple-negative breast cancer (TNBC), who have a high incidence of BM and for whom there are currently no approved targeted therapies [9, 18-20].

Etirinotecan pegol (EP) is a novel long-acting topoisomerase-1 inhibitor designed to improve safety and efficacy of irinotecan by generating lower peak plasma concentrations, significantly extending the effective halflife of the SN38, the active moiety of irinotecan, from 2 to approximately 38 days [21], and concentrate deposition of the parent drug within tumor tissue. Using an experimental mouse model with established BM, a significant reduction in both the number and size of established $\mathrm{BM}$ and a $50 \%$ survival rate were reported for mice treated with EP; surviving animals harbored only minimal residual disease [21-23]. These findings support the ability of EP to cross the blood-tumor barrier, leading to preferential accumulation and retention in BM, followed by sustained exposure to $\mathrm{SN} 38$ at concentrations leading to cytotoxicity.

In the phase 3 BEACON (BrEAst Cancer Outcomes with NKTR-102) trial, patients with heavily pretreated MBC were randomized 1:1 to EP or single-agent treatment of physician's choice (TPC) [24]. The trial allowed inclusion of patients with a history of treated, stable BM. To assess the efficacy of EP in these patients, pre-specified subgroup analyses of efficacy and safety were conducted and are reported herein. In addition, we report a post hoc analysis of survival stratified retrospectively according to the validated breast cancer-specific Graded Prognostic Assessment (GPA) index [25, 26]. 


\section{Materials and methods}

\section{Patients}

Patients eligible for the BEACON study were women (18 years or older) with an Eastern Cooperative Oncology Group (ECOG) performance status (PS) of 0 or 1 ; had histologically or cytologically confirmed carcinoma of the breast; measurable (by Response Evaluation Criteria in Solid Tumors [RECIST] version 1.1) [27] or non-measurable disease; prior therapy (in neoadjuvant, adjuvant and/or metastatic setting) with an anthracycline (unless not medically appropriate or contraindicated), a taxane, and capecitabine; and received between 2 and 5 prior cytotoxic regimens for locally recurrent and/or $\mathrm{MBC}$, with the last dose of cytotoxic chemotherapy within 6 months of randomization. Patients with a history of BM were eligible provided their BM were symptomatically and radiologically stable, local therapy (surgery, whole brain or stereotactic radiation) had been completed, and corticosteroids for this indication had been discontinued $\geq 3$ weeks prior to randomization. Signs and/or symptoms of BM had to have been stable for $\geq 28$ days prior to randomization. Radiologic assessment of the brain at screening was required in patients with focal neurological signs or known BM. Patients with symptomatic or radiologic progression (according to RECIST v1.1) of BM at screening, leptomeningeal disease, or meningeal carcinomatosis were excluded.

\section{Study design}

The study design, methodology, and results for primary and selected secondary endpoints have been previously reported [24]. A preplanned analysis was conducted in the subgroup of patients with a history of treated, stable BM at the time of study enrollment. The study was conducted according to the Declaration of Helsinki and under the principles of the International Conference on Harmonization Good Clinical Practice standards. All patients provided written informed consent, and the study was approved by relevant institutional review board or independent ethics committee.

\section{Administration of study treatments}

EP $\left(145 \mathrm{mg} / \mathrm{m}^{2}\right)$ was administered every 21 days as a 90-min infusion. TPC options were defined in the protocol as single-agent eribulin, ixabepilone, vinorelbine, gemcitabine, paclitaxel, docetaxel, or nab-paclitaxel and administered according to local practice, with the exception of eribulin and ixabepilone, which were administered according to local product labeling. Prior to randomization, the investigator selected and centrally registered the relevant TPC agent.

\section{Assessments}

Radiological examination was required $\leq 28$ days prior to randomization and every 8 weeks ( \pm 7 days) thereafter until progressive disease (PD) was noted. The same imaging modality was required for subsequent radiographic assessment, whether there was measurable or non-measurable disease (RECIST v1.1). Adverse events (AEs) were assessed from the first dose of treatment until 30 days after the last dose and graded according to the National Cancer Institute (NCI) Common Toxicity Criteria for Adverse Events (CTCAE), version 4.0.

\section{Statistical methodology}

Based on a planned sample size of 840 patients $(420$ patients per treatment arm), the BEACON trial had $90 \%$ power to detect a hazard ratio of 0.77 for overall survival (OS) based on death from any cause, with a two-sided alpha level of 0.049. Patients were stratified for geographical region, receptor subtype, and prior eribulin use (patients were not stratified for a history of BM). Patients with a history of treated, stable BM (BCBM subgroup) were assessed for efficacy in terms of OS (time from randomization to death from any cause), progression-free survival (PFS; time to the earliest evidence of documented disease progression as assessed by the investigator or death from any cause), and systemic objective response rate (ORR; proportion of patients with measurable disease at baseline and a confirmed complete response, partial response, stable disease, or PD by RECIST v1.1 criteria). Kaplan-Meier (KM) estimates of survival were summarized and displayed graphically; two-sided unstratified logrank tests were used to compare OS and PFS between treatment groups. For OS (primary analysis), patients not reported as having died at the time of the data cut-off were censored at the date they were last known to be alive. Hazard ratios (HR) for EP versus TPC and corresponding 95\% confidence intervals (CI) were estimated using an unstratified Cox regression model. All $P$-values reported are exploratory; no adjustments were made for the exploratory analyses in the BCBM subgroup.

Survival data were also evaluated in an exploratory post hoc analysis using the GPA index [26]. To calculate GPA, ECOG PS was converted to Karnofsky performance score (KPS) (Table S1) and receptor status (human epidermal growth factor receptor 2 [HER2], estrogen receptor, and progesterone receptor) defined tumor subtype (HER2-positive, Basal, Luminal A, Luminal B) (Table S2). GPA 
scores range from 0 (worst prognosis) to 4 (best prognosis) and grouped as $0-2.0$ and 2.5-4.0. ORR was based on investigator-assessed measurable disease at baseline; Fischer's exact test and Clopper-Pearson exact two-sided 95\% CI were calculated for each arm accordingly. The maximum NCI CTCAE grade and frequency of AEs were compared between the BCBM treatment groups. AEs were summarized for patients who received at least one study drug dose. Odds ratios comparing EP versus TPC were calculated for selected AEs occurring in $\geq 10 \%$ of patients.

\section{Results}

Of the 852 patients randomized in the BEACON trial at 135 medical centers between December 2011 and August 2013, 67 patients had a history of treated, stable BM (EP arm, $n=36$; TPC arm, $n=31$ ). Of these, 19 patients randomized to EP and 18 randomized to TPC had radiologically detectable BM at study entry. Of the 67 patients, 61 (91\%; 34 out of 36 patients in EP and 27 out of 31 patients in TPC) had received prior radiotherapy to their BM; 11 patients $(16 \%)$ had undergone surgical resection, most in combination with radiotherapy. Time from initial BM diagnosis was similar between the two groups: 0.91 and 0.58 years for the EP and TPC groups, respectively. Median time since last brain-directed radiotherapy to first study treatment was also similar between the two groups: 7.8 and 6.7 months for the EP and TPC groups, respectively.

As denoted in Table 1, BCBM patients had similar patient and disease characteristics at baseline to those of the overall BEACON intention-to-treat (ITT) population. In BCBM patients, critical baseline prognostic features were balanced between the two groups (including central nervous system (CNS)-directed therapy, patients with TNBC, median time since diagnosis of breast cancer and a diagnosis of BM, and GPA score). Some marginal differences in baseline features observed baseline ECOG PS 0 (30.6\% of patients in EP arm vs. $16.1 \%$ in TPC arm) and liver involvement $(72.2 \%$ vs. $58.1 \%$ in the EP and TPC arms, respectively). The median number of days of study drug exposure for patients in the BCBM population was similar between treatment arms (47.5 days for EP and 44 days for TPC); both treatment arms received a median number of three cycles. The maximum number of study drug cycles was 23 for EP and 13 for TPC. Of the patients receiving TPC, the majority received multiple (weekly) infusions in each treatment cycle (four patients received a single infusion every 3 weeks).

\section{Efficacy}

With a median follow-up of 21.1 months for the EP arm and 21.7 months for the TPC arm in the primary survival analysis, a total of 60 deaths occurred in the 67 BCBM patients; $31(86.1 \%)$ in the EP arm and $29(93.5 \%)$ in the TPC arm. Median OS was 10.0 months $(95 \%$ CI 7.8-15.7 months) versus 4.8 months $(95 \% \quad \mathrm{CI}$ 3.7-7.3 months) for patients randomized to EP and TPC, respectively (Table 2); KM-curves are shown in Fig. 1, demonstrating a HR of 0.51 (95\% CI 0.30-0.86) favoring EP. Overall survival results favored EP regardless of type of prior BM therapy [for surgery, patients randomized to EP had a median OS of 13.5 months compared to 3.2 months for TPC (HR 0.38); for radiotherapy, 10.0 and 5.1 months, respectively (HR 0.56)] or tumor subtype [HER2-positive, 16.1 vs. 8.6 months (HR 0.55); TNBC, 6.7 vs. 3.8 months (HR 0.27); and hormone receptor-positive, 12.2 vs. 5.2 months (HR 0.47)].

Considerable improvements in 6- and 12-month survival rates were also associated with EP treatment. The 6-month rates were 72.2 and $45.2 \%$ for EP and TPC, respectively; corresponding 12-month rates were 44.4 and 19.4\%, respectively. Forest plot of HRs, with corresponding $95 \%$ CIs and $P$ value, for OS in preselected prognostic factors is shown in Fig. 2. As depicted, there was consistency of benefit across all subgroups favoring EP treatment. In those patients with radiologically detectable but stable and treated BM on baseline imaging, median OS was 13.2 months for EP $(n=19)$ versus 5.8 months for TPC $(n=18)$ (HR 0.45 ; $95 \%$ CI $0.22-0.92$ ) (Fig. 1). The proportion of patients alive at 6 and 12 months were 89.5 versus $50 \%$, and 57.9 versus $22.2 \%$ for the EP and TPC arms, respectively. The median PFS was 3.1 months for EP and 2.7 months for TPC (HR 0.84; 95\% CI 0.49-1.43; $P=0.52$ ) (Fig. 1). PFS rates at 3 months were similar between arms at 50\%; 6-month PFS was 28.6 and $19.5 \%$ in the EP and TPC arms, respectively (Table 2).

All BCBM patients had at least one extra-cranial site of metastasis at baseline: $66 \%$ had liver metastases and $72 \%$ had 3 or more sites of metastatic disease. Among BCBM patients who had measurable systemic disease at baseline (EP, $n=32$; TPC, $n=27$ ), 5 (15.6\%) had a systemic ORR in the EP arm compared with 1 (3.7\%) patient in TPC group (Table 2); all were partial responses. No intra-cranial responses were seen. Of the remaining patients, approximately one-third in each arm had stable disease. For the five patients with a response in the EP arm, median response duration was 5.6 months; response duration in the single responder in the TPC group was 3.7 months. 
Table 1 Demographics and baseline patient characteristics

\begin{tabular}{|c|c|c|c|}
\hline & \multicolumn{2}{|l|}{$\mathrm{BMH}$} & \multirow{2}{*}{$\begin{array}{l}\text { ITT } \\
\text { Total }(n=852)\end{array}$} \\
\hline & Etirinotecan pegol $(n=36)$ & TPC $(n=31)$ & \\
\hline \multicolumn{4}{|l|}{ Demographics } \\
\hline Age (years), median & 54.5 & 54.0 & 55.0 \\
\hline Range & $28-75$ & $37-76$ & $28-84$ \\
\hline \multicolumn{4}{|l|}{ ECOG PS, baseline } \\
\hline 0 & $11(30.6 \%)$ & $5(16.1 \%)$ & $309(36.3 \%)$ \\
\hline 1 & $25(69.4 \%)$ & $25(80.6 \%)$ & $537(63.0 \%)$ \\
\hline 2 & 0 & $1(3.2 \%)$ & $5(0.6 \%)$ \\
\hline 3 & 0 & 0 & $1(0.1 \%)$ \\
\hline \multicolumn{4}{|l|}{ Cancer history } \\
\hline Time since BC diagnosis (years), median & 4.4 & 5.2 & 5.6 \\
\hline Time since LR/MBC diagnosis (years), median & 2.6 & 2.4 & 2.5 \\
\hline Initial disease-free interval (years), median & 2.3 & 3.1 & 2.7 \\
\hline Time since brain metastases diagnosis (years) & 0.91 & 0.58 & NA \\
\hline Visceral disease at enrollment & $30(83.3 \%)$ & $27(87.1 \%)$ & $643(75.5 \%)$ \\
\hline \multicolumn{4}{|l|}{ Metastatic involvement at study entry } \\
\hline Bones & $27(75.0 \%)$ & $13(41.9 \%)$ & $489(57.4 \%)$ \\
\hline Brain & $19(52.8 \%)$ & $18(58.1 \%)$ & $37(4.3 \%)$ \\
\hline Liver & $26(72.2 \%)$ & $18(58.1 \%)$ & $456(53.5 \%)$ \\
\hline Lung & $15(41.7 \%)$ & $15(48.4 \%)$ & $323(37.9 \%)$ \\
\hline \multicolumn{4}{|l|}{ Hormone receptor status } \\
\hline Positive (ER+ or PR+) & $25(69.4 \%)$ & $21(67.7 \%)$ & $585(68.7 \%)$ \\
\hline Negative & $11(30.6 \%)$ & $10(32.3 \%)$ & $266(31.2 \%)$ \\
\hline \multicolumn{4}{|l|}{ HER2/neu receptor status } \\
\hline Positive & $4(11.1 \%)$ & $5(16.1 \%)$ & $62(7.3 \%)$ \\
\hline Negative & $32(88.9 \%)$ & $26(83.9 \%)$ & $782(91.8 \%)$ \\
\hline Triple negative & $10(27.8 \%)$ & $8(25.8 \%)$ & $236(27.7 \%)$ \\
\hline \multicolumn{4}{|l|}{ Prior therapy } \\
\hline Number of prior regimens for $\mathrm{MBC}$, median & 3.0 & 3.0 & 3.0 \\
\hline Anthracycline & $34(94.4 \%)$ & $30(96.8 \%)$ & $816(95.8 \%)$ \\
\hline Refractory $^{\mathrm{a}}$ & $6(16.7 \%)$ & $3(9.7 \%)$ & $115(13.5 \%)$ \\
\hline Taxane & $36(100.0 \%)$ & $31(100.0 \%)$ & $852(100.0 \%)$ \\
\hline Refractory $^{\mathrm{a}}$ & $18(50.0 \%)$ & $13(41.9 \%)$ & $343(40.3 \%)$ \\
\hline Capecitabine & $36(100.0 \%)$ & $31(100.0 \%)$ & $852(100.0 \%)$ \\
\hline Refractory $^{\mathrm{a}}$ & $26(72.2 \%)$ & $19(61.3 \%)$ & $624(73.2 \%)$ \\
\hline Eribulin & $7(19.4 \%)$ & $9(29.0 \%)$ & $143(16.8 \%)$ \\
\hline Hormonal therapy & $25(69.4 \%)$ & $19(61.3 \%)$ & $609(71.5 \%)$ \\
\hline HER2-directed therapies ${ }^{b}$ & $6(16.7 \%)$ & $5(16.1 \%)$ & $87(10.2 \%)$ \\
\hline \multirow[t]{3}{*}{ Prior RT to brain } & $34(94.4 \%)$ & $27(87.0 \%)$ & \\
\hline & Etirinotecan pegol & ТPC & \\
\hline & $\mathrm{BMH}(n=34)$ & $\mathrm{BMH}(n=27)$ & ITT $(n=406)$ \\
\hline \multicolumn{4}{|l|}{ Drug exposure } \\
\hline \multicolumn{4}{|l|}{ Therapy received in TPC } \\
\hline Eribulin & & $8(29.6 \%)$ & $164(40.4 \%)$ \\
\hline Vinorelbine & & $5(18.5 \%)$ & $94(23.2 \%)$ \\
\hline Gemcitabine & & $9(33.3 \%)$ & $71(17.5 \%)$ \\
\hline$n a b$-Paclitaxel & & $3(11.1 \%)$ & $31(7.6 \%)$ \\
\hline
\end{tabular}


Table 1 continued

\begin{tabular}{|c|c|c|c|c|c|}
\hline & & \multicolumn{2}{|c|}{ Etirinotecan pegol } & \multicolumn{2}{|l|}{ TPC } \\
\hline & & $\mathrm{BMH}(n=34)$ & ITT $(n=425)$ & $\mathrm{BMH}(n=27)$ & ITT $(n=406)$ \\
\hline \multicolumn{2}{|l|}{ Paclitaxel } & & & 0 & $18(4.4 \%)$ \\
\hline \multicolumn{2}{|l|}{ Ixabepilone } & & & $1(3.7 \%)$ & $15(3.7 \%)$ \\
\hline \multicolumn{2}{|l|}{ Docetaxel } & & & $1(3.7 \%)$ & $13(3.2 \%)$ \\
\hline \multicolumn{2}{|c|}{ Exposure duration (days), median (range) } & $47.5(1-540)$ & $48(1-766)$ & $44(1-376)$ & $56.5(1-607)$ \\
\hline \multicolumn{2}{|c|}{ Number of cycles completed, median (range) } & $3(1-23)$ & $3(1-35)$ & $3(1-13)$ & $3(1-26)$ \\
\hline & \multicolumn{5}{|l|}{$\mathrm{BMH}$} \\
\hline & \multicolumn{2}{|c|}{ Etirinotecan pegol $(n=36)$} & \multicolumn{2}{|c|}{ TPC $(n=31)$} & Total $(n=67)$ \\
\hline \multicolumn{6}{|c|}{ Graded prognostic assessment (GPA) index } \\
\hline \multicolumn{6}{|l|}{ Score } \\
\hline $0-2$ & \multicolumn{2}{|c|}{$13(36.1 \%)$} & \multicolumn{2}{|c|}{$10(32.3 \%)$} & $23(34.3 \%)$ \\
\hline $2.5-4$ & \multicolumn{2}{|c|}{$23(63.9 \%)$} & \multicolumn{2}{|c|}{$21(67.7 \%)$} & $44(65.7 \%)$ \\
\hline Median/mean score & \multicolumn{2}{|c|}{$2.3 / 2.5$} & \multicolumn{2}{|c|}{$2.3 / 2.5$} & $2.3 / 2.5$ \\
\hline \multicolumn{6}{|c|}{$\begin{array}{l}B C \text { breast cancer, } B M H \text { history of treated, stable breast cancer brain metastases, } E C O G \text { Eastern Cooperative Oncology Group, } E R \text { estrogen } \\
\text { receptor, } G P A \text { graded prognostic assessment, } H E R 2 \text { human epidermal receptor type } 2, I T T \text { intention-to-treat, } L R \text { locally recurrent, } M B C \\
\text { metastatic breast cancer, } P R \text { progestin receptor, } P S \text { performance status, } R T \text { radiation therapy, } T P C \text { treatment of physician's choice }\end{array}$} \\
\hline
\end{tabular}

\section{Graded prognostic assessment index}

The treatment groups were well balanced for GPA indices (KPS, tumor subtype, and age) at baseline. Of the 67 patients, 23 had low ( $0-2$; i.e., poorer prognosis) GPA scores and 44 had higher (2.5-4; i.e., better prognosis) scores. Thirty-six percent of patients in the EP arm had low GPA scores versus $32 \%$ for the TPC arm; both mean and median GPA scores for the treatment groups were the same (mean 2.3, median 2.5; Table 1). The median OS for patients with a GPA of 0-2 was 7.8 months in the EP arm and 3.8 months in the TPC arm (HR $0.27 ; 95 \%$ CI $0.10-0.72 ; \quad P<0.01$ ) (Table 2). The median OS for patients with a GPA of 2.5-4 was 13.2 months for EP and 6.9 months for TPC (HR 0.54; 95\% CI 0.28-1.04; $P=0.062$ ). The HR for OS of the 67 patients after adjusting for the two GPA groups was 0.44, favoring EP.

The same analyses were conducted for patients who had radiologically detectable but stable $\mathrm{BM}$ on baseline imaging. In this smaller group (EP, $n=19$; TPC, $n=18$ ), the same trend was seen. The median OS for patients with a GPA of 0-2 was 9.6 months for EP and 3.5 months for TPC; median OS for patients with a GPA of 2.5-4.0 was 16.8 and 6.9 months, respectively.

\section{Safety}

Sixty-one patients comprised the safety population, 34 in the EP arm and 27 in the TPC arm ( 2 and 4 patients, respectively, were randomized but did not proceed to treatment due to withdrawal of consent or rapid deterioration of PS). The proportion of patients who experienced at least one grade 3 or higher treatment-emergent $\mathrm{AE}$ was lower in the EP arm compared with TPC (50\% vs. $70.4 \%$, respectively; Table 3). Neutropenia, the most common grade $\geq 3 \mathrm{AE}$, occurred in $33.3 \%$ of TPC patients versus $14.7 \%$ EP patients. The incidence of grade 3 diarrhea was nearly identical in the two study arms, 5.9 versus $3.7 \%$ in the EP and TPC arms, respectively. Treatment discontinuation was attributed to an $\mathrm{AE}$ in seven patients in the $\mathrm{EP}$ arm (neutropenia or neutrophil count, $n=3$; diarrhea, $n=2$; ascites, $n=1$; and vomiting, $n=1$ ) and 1 patient in the TPC arm (confusional state, $n=1$ ).

In the BEACON ITT population, a longitudinal analysis using repeated measure linear mixed model in change from baseline over 32 weeks showed that EP was statistically superior $(P<0.02)$ in the treatment difference for global health status and physical functioning and numerically superior in all other functions. The mean difference between treatment groups was larger in the BCBM patients, although the sample size was too small to detect statistical significance $(P>0.05)$.

\section{Post-study treatment}

In the BCBM subgroup, $72.2 \%$ of those randomized to EP received at least one subsequent cancer therapy versus $48.4 \%$ randomized to TPC. Eribulin and gemcitabine were 
Table 2 Efficacy

\begin{tabular}{|c|c|c|c|}
\hline & Etirinotecan pegol $(n=36)$ & TPC $(n=31)$ & $P$-value \\
\hline \multicolumn{4}{|l|}{ BMH subgroup } \\
\hline Objective response rate (systemic) & $5(15.6 \%)$ & $1(3.7 \%)$ & 0.20 \\
\hline Evaluable population $^{\mathrm{a}}$ & $n=32$ & $n=27$ & \\
\hline $95 \% \mathrm{CI}$ & $5.3-32.8$ & $0.1-19.0$ & \\
\hline Complete response & 0 & 0 & \\
\hline Partial response & $5(15.6 \%)$ & $1(3.7 \%)$ & \\
\hline Stable disease & $9(28.1 \%)$ & $9(33.3 \%)$ & \\
\hline Progressive disease & $14(43.8 \%)$ & $9(33.3 \%)$ & \\
\hline Not evaluable & $4(12.5 \%)$ & $8(29.6 \%)$ & \\
\hline \multicolumn{4}{|l|}{ Overall survival (months) } \\
\hline Median & 10.0 & 4.8 & $<0.01$ \\
\hline $95 \% \mathrm{CI}$ & $7.8-15.7$ & $3.7-7.3$ & \\
\hline 6-month OS rate & $72.2 \%$ & $45.2 \%$ & \\
\hline 12-month OS rate & $44.4 \%$ & $19.4 \%$ & \\
\hline Progression-free survival (months) & & & \\
\hline Median & 3.1 & 2.7 & 0.52 \\
\hline $95 \% \mathrm{CI}$ & $1.8-4.0$ & $1.8-3.7$ & \\
\hline 3-month PFS rate & $50.1 \%$ & $50.0 \%$ & \\
\hline 6-month PFS rate & $28.6 \%$ & $19.5 \%$ & \\
\hline & Etirinotecan pegol $(n=19)$ & ТPC $(n=18)$ & $P$-value \\
\hline Radiologically detectable brain lesions at & & & \\
\hline Objective response rate (systemic) & $4(25 \%)$ & $1(6.3 \%)$ & 0.33 \\
\hline Evaluable population $^{\mathrm{a}}$ & $n=16$ & $n=16$ & \\
\hline $95 \% \mathrm{CI}$ & $7.3-52.4$ & $0.2-30.2$ & \\
\hline Complete response & 0 & 0 & \\
\hline Partial response & $4(25.0 \%)$ & $1(6.3 \%)$ & \\
\hline Stable disease & $5(31.3 \%)$ & $6(37.5 \%)$ & \\
\hline Progressive disease & $6(37.5 \%)$ & $4(25.0 \%)$ & \\
\hline Not evaluable & $1(6.3 \%)$ & $5(31.3 \%)$ & \\
\hline Progressive disease in brain lesion & $6(37.5 \%)$ & $6(37.5 \%)$ & \\
\hline Overall survival (months) & & & \\
\hline Median & 13.2 & 5.8 & 0.02 \\
\hline $95 \% \mathrm{CI}$ & $8.6-19.6$ & $3.5-8.6$ & \\
\hline 6-month survival rate & $89.5 \%$ & $50.0 \%$ & \\
\hline 12-month survival rate & $57.9 \%$ & $22.2 \%$ & \\
\hline OS by GPA category—BMH Subgroup & Etirinotecan pegol $(n=36)$ & ТPC $(n=31)$ & $P$-value \\
\hline $0-2$ & & & \\
\hline $\mathrm{n}$ & 13 & 10 & \\
\hline Median, months & 7.8 & 3.8 & $<0.01$ \\
\hline $2.5-4$ & & & \\
\hline $\mathrm{n}$ & 23 & 21 & \\
\hline Median, months & 13.2 & 6.9 & 0.06 \\
\hline OS by GPA category—radiologically det & lesions at baseline & TPC $(n=18)$ & $P$-value \\
\hline $0-2$ & & & \\
\hline $\mathrm{n}$ & 6 & 5 & \\
\hline
\end{tabular}


Table 2 continued

\begin{tabular}{lll}
\hline OS by GPA category_radiologically detectable brain lesions at baseline & Etirinotecan pegol $(n=19)$ & TPC $(n=18)$ \\
\hline Median, months & 9.6 & 3.5 \\
$2.5-4$ & 13 & 13 \\
$\mathrm{n}$ & 16.8 & 6.9 \\
Median, months & &
\end{tabular}

${ }^{a}$ Efficacy evaluable population (measureable systemic disease at baseline required)

$B M H$ history of treated, stable breast cancer brain metastases, $C I$ confidence interval, GPA graded prognostic assessment, $O S$ overall survival, $P F S$ progression-free survival, $S D$ stable disease, TPC treatment of physician's choice

the most commonly prescribed follow-on therapies in patients randomized to EP (41.7 and $27.8 \%$, respectively); the most commonly prescribed subsequent therapies in the TPC arm were paclitaxel (12.9\%) and cyclophosphamide $(12.9 \%)$. Use of eribulin (combining those patients who had received eribulin prior to study, as part of the TPC group or as follow-on therapy) was similar between the two groups. For the EP group, 7 (19.4\%) patients received eribulin prior to study and $15(41.7 \%)$ patients as a followon therapy. For the TPC group, 9 (29.0\%) patients received prior eribulin; $8(25.8 \%)$ patients had eribulin as their TPC agent, and $2(6.5 \%)$ as follow-on therapy.

\section{Discussion}

In the overall BEACON study, EP was associated with a 2.1-month improvement in OS compared to TPC; however, statistical significance was not reached (HR 0.87; 95\% CI $0.75,1.02 ; P=0.08$ ) [24]. In a preplanned subgroup analysis of patients with a history of stable, treated BM, EP demonstrated a substantial reduction in the risk of death (HR 0.51) compared to conventional chemotherapy. Median survival was improved by 5.2 months (10.0 vs. 4.8 months), with a doubling of 12 -month survival rate (44 vs. 20\%). Findings were even more pronounced in the small subset of patients with radiologically detectable, but stable, brain lesions at baseline, with a 7.4-month survival advantage for those patients receiving EP.

In a post hoc evaluation using the GPA Index as described herein, treatment with EP was associated with improved OS for patients in both better and worse prognosis groups, reinforcing the activity of EP in BCBM patients. The GPA tool, which assigns scores for significant prognostic indices of KPS, tumor subtype, and age, was originally developed to predict prognosis in patients with newly diagnosed BM $[25,26]$. It should be noted that many of the BCBM patients in this analysis were not newly diagnosed with BM; however, the GPA analysis provided a way to stratify patients to correct for potential imbalances between the groups, most notably the differences in HER2 and performance status.
All BCBM patents randomized into BEACON had extra-cranial disease, the majority of whom (72\%) had a high burden of systemic disease (defined as three or more sites of metastases). This is consistent with the rarity of CNS lesions being the solitary site of disease in MBC, occurring in fewer than 5\% [28]. Most BCBM patients die from progression of systemic (extra-cranial) disease or a combination of extra-cranial and intra-cranial progression. In one series of 83 patients with BCBM, only $15 \%$ died of isolated CNS disease progression with stable systemic disease at the time of death [29]. Hence, control of both intra-cranial and extra-cranial disease is crucial. No intracranial objective responses were seen in BCBM patients randomized to either EP or TPC; however, two patients in the EP arm had non-target CNS lesions (present at baseline) become absent during their course of treatment. Of note, BCBM patients in the BEACON study were required to have had all CNS lesions treated (with either radiotherapy or surgery) and no evidence of radiographic progression or neurological symptoms prior to randomization. As such, all brain lesions present at study entry were considered non-target lesions by RECIST and best overall "in-brain response" could therefore be a complete response, "non- $\mathrm{CR}$, non-PD," or progression. The ongoing phase three trial in BCBM patients (ClinicalTrials.gov NCT02915744) uses the more recently introduced RANOBR criteria [30], which assesses intra-cranial and extracranial disease independently for both response and progression.

Unselected, retrospective, historical data indicate that median survival of patients with brain metastases from breast cancer after radiation therapy is approximately 4-6 months [31-33], and varies depending on prognostic factors from 3.4 months to 2 years $[25,26]$. We acknowledge that the results reported herein are in a highly selected patient population and that the lack of systematic brain assessment is a limitation of the study (head imaging was only required at baseline and follow-up for patients with focal neurological deficits or a known history of brain metastases). However, as a recent review of the literature emphasizes, there is a relative paucity of data in this patient population, with only small prospective trials evaluating 
Fig. 1 Kaplan-Meier estimates for a overall survival and b progression-free survival for patients with stable, treated brain metastases; and c overall survival for patients with radiologically detectable, but stable, brain lesions at study entry. $C I$ confidence interval, $H R$ hazard ratio, $m O S$ median overall survival, $m P F S$ median progression-free survival, TPC treatment of physician's choice
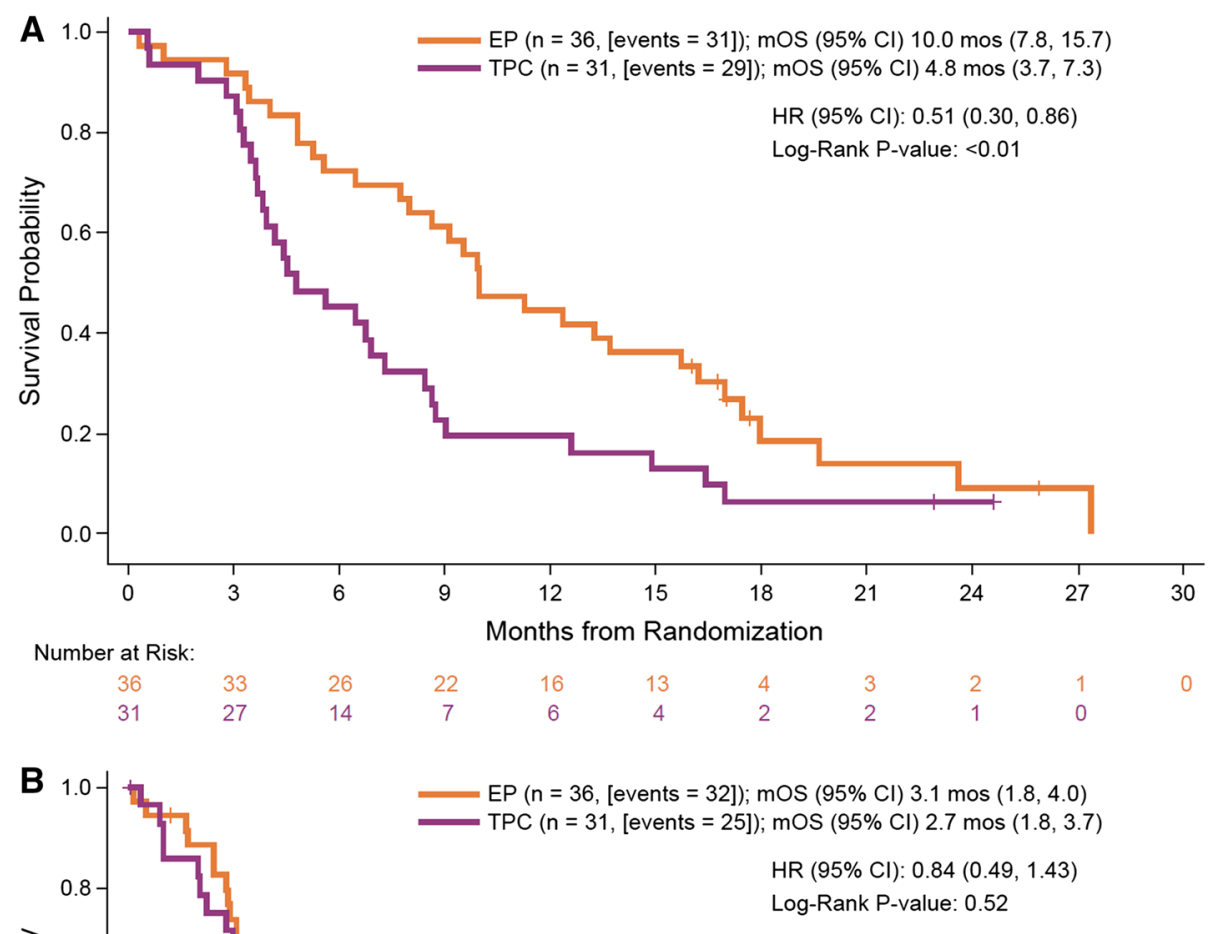

Log-Rank P-value: 0.52

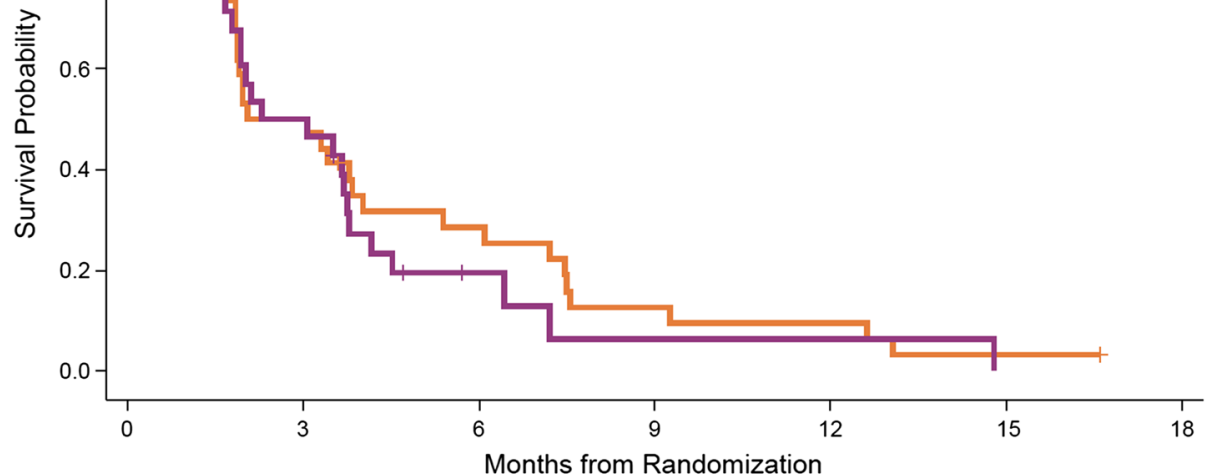

Number at Risk:

$\begin{array}{lllllll}36 & 17 & 9 & 4 & 3 & 1 & 0 \\ 31 & 14 & 3 & 1 & 1 & 0 & \end{array}$

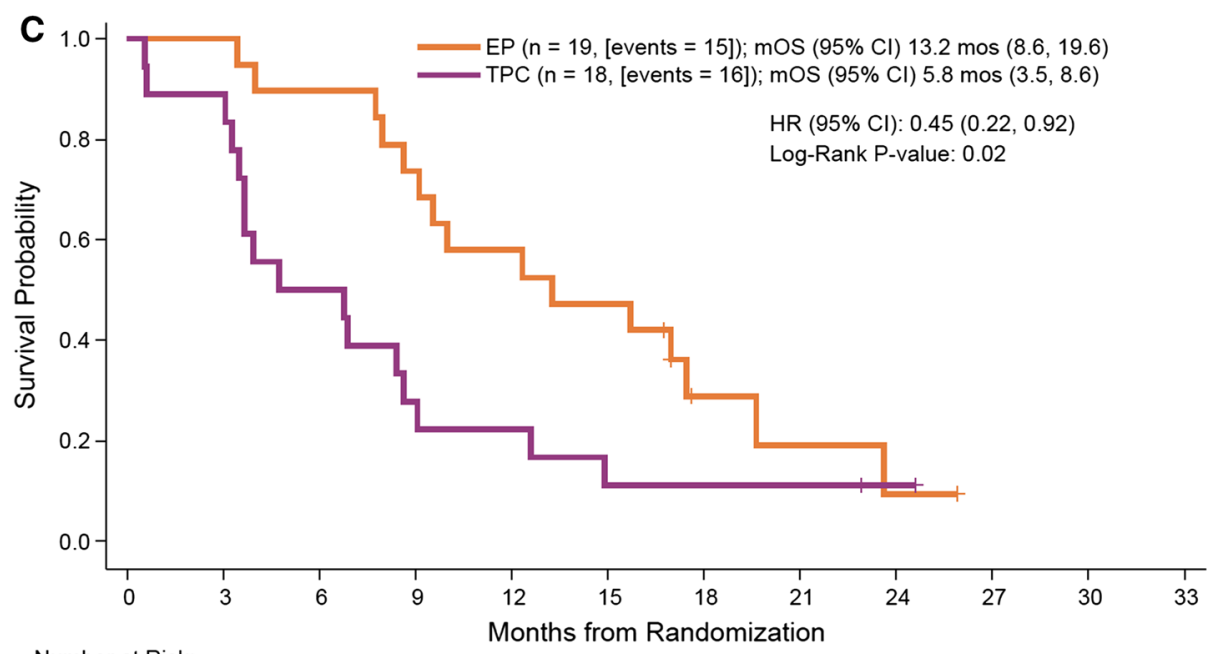

Number at Risk:

$\begin{array}{lrrrrrrrrr}19 & 19 & 17 & 14 & 11 & 9 & 3 & 2 & 1 & 0 \\ 18 & 16 & 9 & 5 & 4 & 2 & 2 & 2 & 1 & 0\end{array}$




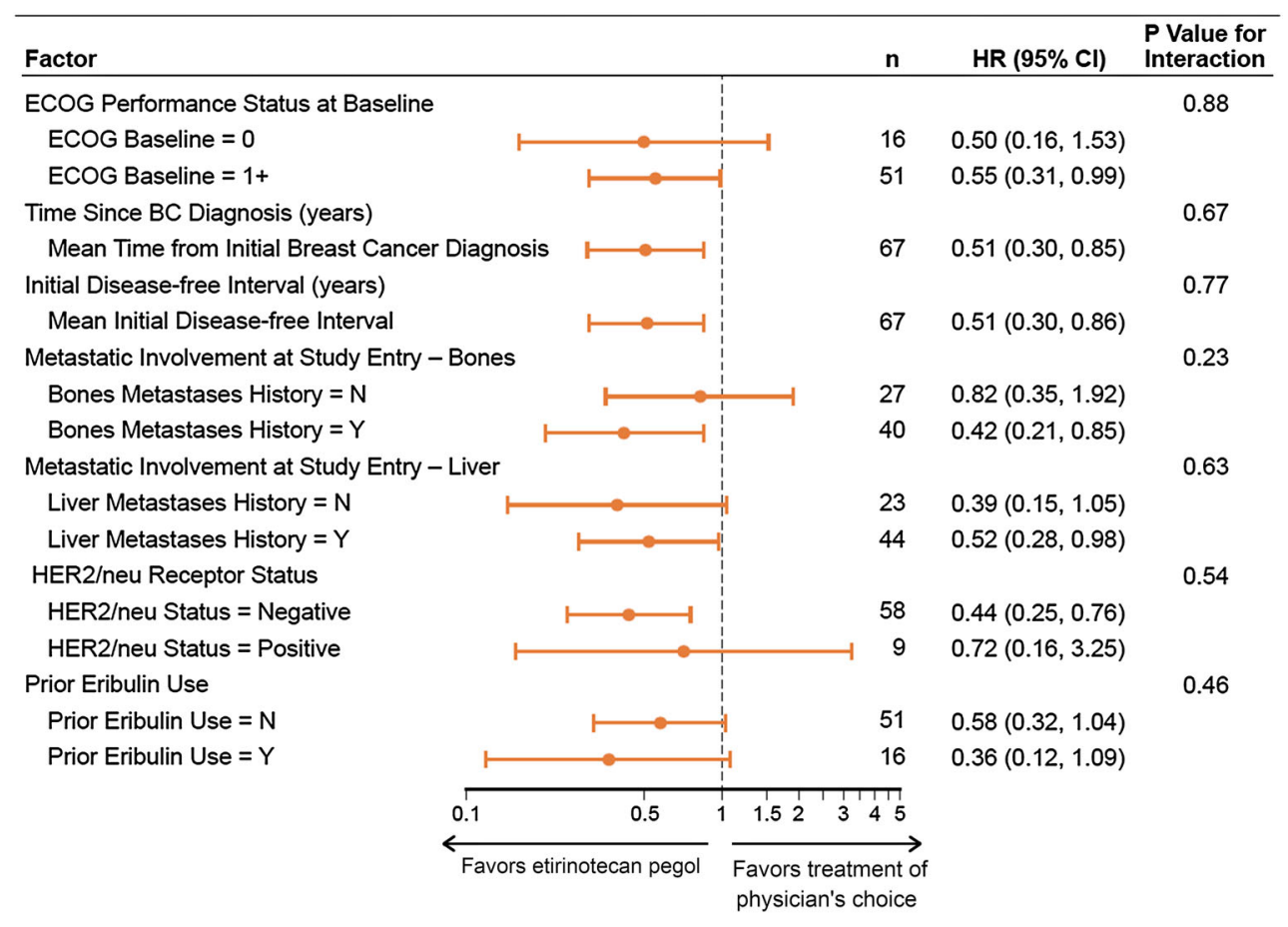

Fig. 2 Forest plot of hazard ratios (HR) with 95\% confidence intervals (CI) for overall survival for selected prognostic factors in the intention-to-treat (ITT) population with a history of treated, stable brain metastases. $B C$ breast cancer, $C I$ confidence interval,
ECOG Eastern Cooperative Oncology Group, HER2 human epidermal growth factor receptor 2, $H R$ hazard ratio, $T P C$ treatment of physician's choice

Table 3 Common grade 3 or higher adverse events

\begin{tabular}{|c|c|c|c|c|}
\hline & \multicolumn{2}{|c|}{ Etirinotecan pegol } & \multicolumn{2}{|l|}{ TPC } \\
\hline & $\mathrm{BMH}(n=34)$ & ITT $(n=425)$ & $\mathrm{BMH}(n=27)$ & ITT $(n=406)$ \\
\hline Number of patients with at least one AE grade 3 or higher & $17(50.0 \%)$ & $204(48.0 \%)$ & $19(70.4 \%)$ & $256(63.1 \%)$ \\
\hline \multicolumn{5}{|l|}{ Hematologic } \\
\hline Neutropenia-related events & $5(14.7 \%)$ & $41(9.6 \%)$ & $9(33.3 \%)$ & $125(30.8 \%)^{\mathrm{b}}$ \\
\hline Anemia & $1(2.9 \%)^{\mathrm{a}}$ & $20(4.7 \%)^{\mathrm{a}}$ & $1(3.7 \%)$ & $19(4.7 \%)$ \\
\hline \multicolumn{5}{|l|}{ Non-hematologic } \\
\hline Diarrhea & $2(5.9 \%)^{\mathrm{a}}$ & $41(9.6 \%)^{\mathrm{a}}$ & $1(3.7 \%)^{\mathrm{a}}$ & $5(1.2 \%)^{\mathrm{a}}$ \\
\hline Nausea & $2(5.9 \%)^{\mathrm{a}}$ & $15(3.5 \%)^{\mathrm{a}}$ & 0 & $8(2.0 \%)^{\mathrm{a}}$ \\
\hline Pleural effusion & $2(5.9 \%)$ & $15(3.5 \%)$ & 0 & $16(3.9 \%)$ \\
\hline Dehydration & $1(2.9 \%)^{\mathrm{a}}$ & $17(3.5 \%)^{\mathrm{a}}$ & $1(3.7 \%)^{\mathrm{b}}$ & $8(2.0 \%)^{\mathrm{b}}$ \\
\hline Hypokalemia & $1(2.9 \%)$ & $10(2.4 \%)$ & $1(3.7 \%)$ & $7(2.0 \%)$ \\
\hline Hyponatremia & 0 & $3(<1 \%)^{\mathrm{a}}$ & $2(7.4 \%)$ & $8(2.0 \%)$ \\
\hline Neuropathy-related events & 0 & $2(<1 \%)$ & 0 & $15(3.7 \%)^{\mathrm{a}}$ \\
\hline
\end{tabular}

$A E$ adverse event, $B M H$ history of treated, stable breast cancer brain metastases, ITT intention-to-treat, $T P C$ treatment of physician's choice

${ }^{\text {a }}$ No grade 4 reported

b Grade 5 event(s) reported

chemotherapy in patients with BCBM previously treated with either systemic therapy or radiotherapy [11]. The biological rationale for EP accumulation in brain metastases is strong, with results of this study providing solid hypothesis generation. The activity of single-agent EP against intra-cranial malignancies is supported by a phase 2 trial in which 3 of 18 patients with glioblastoma multiforme (GBM) progressing after bevacizumab treatment had confirmed partial responses according to RANO criteria, corresponding to a $17 \%$ response rate; two of the responses were highly durable, lasting $\geq 19$ months [34]. To place this in context, it is rare to see objective responses in 
patients with GBM whose disease has progressed on bevacizumab as evidenced by phase II trials [35-47]. The plausibility of an enhanced survival effect using EP is further strengthened by the non-clinical pharmacology data in mouse models of human tumors including the CNS, comparing EP to either conventional irinotecan or to the TPC agents used in BEACON. The data from two separate studies support differential distribution and markedly longer retention of EP and SN38 active metabolite, with resultant longer survival in mice treated with EP, 100-fold higher brain concentrations and resolution of brain lesions upon necropsy [22, 23].

As a topoisomerase-I inhibitor, SN38 derived from EP has a mechanism of action and a toxicity spectrum that is distinct from that of the tubulin-inhibitor cytotoxic drugs, which comprises most of the standard of care chemotherapies for MBC treatment. In patients with advanced malignancies who have received multiple prior regimens, an alternative mechanism of action is important: it reduces the likelihood of cross-resistance and contribution to cumulative toxicities. In the BEACON trial [24, 48] and the BCBM subgroup, EP demonstrated a lower rate of grade 3 and dose-limiting/QoL-reducing toxicities associated with tubulin-inhibitors (notably neuropathy, myelosuppression, fatigue, cardiomyopathy, and alopecia), although EP was associated with more gastrointestinal toxicities, including diarrhea.

There remains a critical need for therapeutic interventions that prolong patient survival and maintain or improve QoL of patients with breast cancer and brain metastases. Despite the relatively small number of patients in this preplanned subgroup analysis, the clear survival benefit and favorable safety profile demonstrated over that of commonly prescribed agents in this setting, together with phase II evidence of single-agent activity in recurrent highgrade primary brain tumors, support further study of EP as treatment of brain metastases for SN38-sensitive primary tumors including breast cancer. An international phase three trial in this population is underway (ClinicalTrials.gov NCT02915744). Nektar Therapeutics submitted a marketing authorization application for conditional approval of EP in Europe for the treatment of adult patients with breast cancer and brain metastases. The decision regarding conditional approval is expected in 2017.

\begin{abstract}
Acknowledgements We thank the patients, their caregivers and families, and the investigators who participated in this study. We thank the independent Data Monitoring Committee (Drs Kathy Miller, Banu Arun, and James Boyett) for their study oversight. We also thank Phillips Gilmore Oncology Communications for providing medical writing support, funded by Nektar Therapeutics.
\end{abstract}

Funding This study was sponsored by Nektar Therapeutics, San Francisco, CA, USA.

\section{Compliance with ethical standards}

Disclosures JC: advisor: Celgene, Roche; speaker: Celgene, Roche, Eisai, Novartis; partner and stockholder: MedSIR. HSR: research support to UC Regents from Eisai and from Nektar for this trial. AA: advisor: Nektar Therapeutics, Roche, Bayer, Pfizer. CJT: advisor: Nektar Therapeutics. VD: advisor: Roche, Novartis, Pfizer, Nektar, Eisai, Lilly; speaker: Roche, Pfizer, Novartis. CZ, MT, and UH: paid employees of Nektar Therapeutics. ALH: consultant, Nektar Therapeutics. JO: advisor: Nektar Therapeutics. EAP, S-AI, LSS, PG-P, DAY, DAP, AM, AM-A, and J-SA declare no conflicts of interest.

Open Access This article is distributed under the terms of the Creative Commons Attribution 4.0 International License (http://crea tivecommons.org/licenses/by/4.0/), which permits unrestricted use, distribution, and reproduction in any medium, provided you give appropriate credit to the original author(s) and the source, provide a link to the Creative Commons license, and indicate if changes were made.

\section{References}

1. Kennecke H, Yerushalmi R, Woods R, Cheang MC, Voduc D, Speers CH, Nielsen TO, Gelmon K (2010) Metastatic behavior of breast cancer subtypes. J Clin Oncol 28:3271-3277. doi:10.1200/ JCO.2009.25.9820

2. Lin NU, Bellon JR, Winer EP (2004) CNS metastases in breast cancer. J Clin Oncol 22:3608-3617. doi:10.1200/JCO.2004.01. 175

3. Pestalozzi BC, Zahrieh D, Price KN, Holmberg SB, Lindtner J, Collins J, Crivellari D, Fey MF, Murray E, Pagani O, Simoncini E, Castiglione-Gertsch M, Gelber RD, Coates AS, Goldhirsch A; International Breast Cancer Study Group (IBCSG) (2006) Identifying breast cancer patients at risk for central nervous system (CNS) metastases in trials of the International Breast Cancer Study Group (IBCSG). Ann Oncol 17(6):935-944. doi:10.1093/ annonc/mdl064

4. Lin NU, Winer EP (2007) Brain metastases: the HER2 paradigm. Clin Cancer Res 13(6):1648-1655. doi:10.1158/1078-0432.CCR06-2478

5. Lombardi G, Di Stefano AL, Farina P, Zagonel V, Tabouret E (2014) Systemic treatments for brain metastases from breast cancer, non-small cell lung cancer, melanoma and renal cell carcinoma: an overview of the literature. Cancer Treat Rev 40(8):951-959. doi:10.1016/j.ctrv.2014.05.007

6. Soni A, Ren Z, Hameed O, Chanda D, Morgan CJ, Siegal GP, Wei S (2015) Breast cancer subtypes predispose the site of distant metastases. Am J Clin Pathol 143(4):471-478. doi:10.1309/ AJCPYO5FSV3UPEXS

7. Sorlie T, Tibshirani R, Parker J, Hastie T, Marron JS, Nobel A, Deng S, Johnsen H, Pesich R, Geisler S, Demeter J, Perou CM, Lønning PE, Brown PO, Børresen-Dale AL, Botstein D (2003) Repeated observation of breast tumor subtypes in independent gene expression data sets. Proc Natl Acad Sci USA 100:8418-8423

8. Kodack DP, Askoxylakis V, Ferraro G, Fukumura D, Jain R (2015) Emerging strategies for treating brain metastases from breast cancer. Cancer Cell 27(2):163-175. doi:10.1016/j.ccell. 2015.01.001

9. Lin NU, Claus E, Sohl J, Razzak AR, Arnaout A, Winer EP (2008) Sites of distant recurrence and clinical outcomes in patients with metastatic triple-negative breast cancer: high 
incidence of central nervous system metastases. Cancer 113:2638-2645. doi:10.1002/cncr.23930

10. Melisko ME, Moore DH, Sneed PK, De Franco J, Rugo HS (2008) Brain metastases in breast cancer: clinical and pathologic characteristics associated with improvements in survival. J Neurooncol 88:359-365. doi:10.1007/s11060-008-9578-5

11. Lin NU (2013) Breast cancer brain metastases: new directions in systemic therapy. Ecancermedicalscience 7:307. doi:10.3332/ ecancer.2013.307

12. Hambrecht A, Jandial R, Neman J (2011) Emerging role of brain metastases in the prognosis of breast cancer patients. Breast Cancer (Dove Med Press) 3:79-91. doi:10.2147/BCTT.S19967

13. Lim E, Lin NU (2012) New insights and emerging therapies for breast cancer brain metastases. Oncology (Williston Park) 26(652-659):663

14. Arslan C, Dizdar O, Altundaq K (2014) Chemotherapy and biological treatment options in breast cancer patients with brain metastasis: an update. Expert Opin Pharmacother 15(12): 1558-1643. doi:10.1517/14656566.2014.929664

15. Lim E, Lin NU (2014) Updates on the management of breast cancer brain metastases. Oncology (Williston Park) 28(7): 572-578

16. Gabathuler R (2010) Approaches to transport therapeutic drugs across the blood-brain barrier to treat brain diseases. Neurobiol Dis 37(1):48-57. doi:10.1016/j.nbd.2009.07.028

17. Gil-Gil MJ, Martinez-Garcia M, Sierra A, Conesa G, Del Barco S, González-Jimenez S, Villà S (2014) Breast cancer brain metastases: a review of the literature and a current multidisciplinary management guideline. Clin Transl Oncol 16:436-446. doi:10.1007/s12094-013-1110-5

18. Dawood S, Broglio K, Esteva FJ, Yang W, Kau SW, Islam R, Albarracin C, Yu TK, Green M, Hortobagyi GN, Gonzalez-Angulo AM (2009) Survival among women with triple receptornegative breast cancer and brain metastases. Ann Oncol 20(4):621-627. doi:10.1093/annonc/mdn682

19. Niwińska A, Murawska M, Pogoda K (2010) Breast cancer brain metastases: differences in survival depending on biological subtype, RPA RTOG prognostic class and systemic treatment after whole-brain radiotherapy (WBRT). Ann Oncol 21:942-948. doi:10.1093/annonc/mdp407

20. Morris PG, Murphy CG, Mallam D, Accordino M, Patil S, Howard J, Omuro A, Beal K, Seidman AD, Hudis CA, Fornier MN (2012) Limited overall survival in patients with brain metastases from triple negative breast cancer. Breast $\mathbf{J}$ 18(4):345-350. doi:10.1111/j.1524-4741.2012.01246.x

21. Hoch U, Staschen C-M, Johnson R, Eldon MA (2014) Nonclinical pharmacokinetics and activity of etirinotecan pegol (NKTR102), a long-acting topoisomerase 1 inhibitor, in multiple cancer models. Cancer Chemother Pharmacol 74(6):1125-1137. doi:10. 1007/s00280-014-2577-7

22. Adkins CE, Nounou MI, Hye T, Mohammad AS, Terrell-Hall T, Mohan NK, Eldon MA, Hoch U, Lockman PR (2015) NKTR-102 Efficacy versus irinotecan in a mouse model of brain metastases of breast cancer. BMC Cancer 15:685. doi:10.1186/s12885-015$1672-4$

23. Shah N, Mohammad AS, Adkins CE, Dolan EL, Griffith J, Jagannathan R, Ute Hoch, and Lockman PR (2016) Etirinotecan pegol: survival advantage over standard of care drugs in a model of brain metastases of breast cancer. In: $39^{\text {th }}$ Annual CTRCAACR San Antonio Breast Cancer Symposium, San Antonio, TX, USA, December 6-10, 2016 (P1-12-05)

24. Perez EA, Awada A, O'Shaughnessy J, Rugo HS, Twelves C, Im SA, Gómez-Pardo P, Schwartzberg LS, Diéras V, Yardley DA, Potter DA, Mailliez A, Moreno-Aspitia A, Ahn JS, Zhao C, Hoch U, Tagliaferri M, Hannah AL, Cortes J (2015) Etirinotecan pegol (NKTR-102) versus treatment of physician's choice in anthracyline- taxane- and capecitabine-treated advanced breast cancer. Lancet Oncol 16(15):1556-1568. doi:10.1016/S14702045(15)00332-0

25. Sperduto PW, Kased N, Roberge D, Xu Z, Shanley R, Luo X, Sneed PK, Chao ST, Weil RJ, Suh J, Bhatt A, Jensen AW, Brown PD, Shih HA, Kirkpatrick J, Gaspar LE, Fiveash JB, Chiang V, Knisely JP, Sperduto CM, Lin N, Mehta M (2012) Summary report on the graded prognostic assessment: an accurate and facile diagnosis-specific tool to estimate survival for patients with brain metastases. J Clin Oncol 30(4):419-425. doi:10.1200/JCO. 2011.38.0527

26. Sperduto PW, Kased N, Roberge D, Xu Z, Shanley R, Luo X, Sneed PK, Chao ST, Weil RJ, Suh J, Bhatt A, Jensen AW, Brown PD, Shih HA, Kirkpatrick J, Gaspar LE, Fiveash JB, Chiang V, Knisely JP, Sperduto CM, Lin N, Mehta M (2012) Effect of tumor subtype on survival and the graded prognostic assessment (GPA) for patients with breast cancer and brain metastases. Int J Radiat Oncol Biol Phys 82(5):2111-2117. doi:10.1016/j.ijrobp. 2011.02.027

27. Eisenhauer EA, Therasse P, Bogaerts J, Schwartz LH, Sargent D, Ford R, Dancey J, Arbuck S, Gwyther S, Mooney M, Rubinstein L, Shankar L, Dodd L, Kaplan R, Lacombe D, Verweij J (2009) New response evaluation criteria in solid tumors: revised RECIST guideline (version 1.1). Eur J Cancer 45:228-247. doi:10.1016/j.ejca.2008.10.026

28. Witzel I, Oliveira-Ferrer L, Pantel K, Müller V, Wikman H (2016) Breast cancer brain metastases: biology and new clinical perspectives. Breast Cancer Res 18(1):8. doi:10.1186/s13058015-0665-1

29. Eichler AF, Kuter I, Ryan P, Schapira L, Younger J, Henson JW (2008) Survival in patients with brain metastases from breast cancer: the importance of HER-2 status. Cancer 112(11): 2359-2367. doi:10.1002/cncr.23468

30. Lin NU, Lee EQ, Aoyama H, Barani IJ, Barboriak DP, Baumert BG, Bendszus M, Brown PD, Camidge DR, Chang SM, Dancey J, de Vries EG, Gaspar LE, Harris GJ, Hodi FS, Kalkanis SN, Linskey ME, Macdonald DR, Margolin K, Mehta MP, Schiff D, Soffietti R, Suh JH, van den Bent MJ, Vogelbaum MA, Wen PY; Response Assessment in Neuro-Oncology (RANO) group (2015) Response assessment criteria for brain metastases: proposal from the RANO group. Lancet Oncol 16(6):e270-e278. doi:10.1016/ S1470-2045(15)70057-4

31. Fokstuen T, Wilking N, Rutqvist LE, Wolke J, Liedberg A, Signomklao T, Fernberg JO (2000) Radiation therapy in the management of brain metastases from breast cancer. Breast Cancer Res Treat 62:211-216. doi:10.1023/A:1006486423827

32. Saito EY, Viani GA, Ferrigno R, Nakamura RA, Novaes PE, Pellizzon CA, Fogaroli RC, Conte M (2006) Whole brain radiation therapy in management of brain metastasis: results and prognostic factors. Radiat Oncol 1:20. doi:10.1186/1748-717X-120

33. Viani GA, Castilho MS, Salvajoli JA, Pellizzon AC, Novaes PE, Guimarães FS, Conte MA, Fogaroli RC (2007) Whole brain radiotherapy for brain metastases from breast cancer: estimation of survival using two stratification systems. BMC Cancer 7:153. doi:10.1186/1471-2407-7-53

34. Nagpal S, Recht CK, Bertrand S, Thomas RP, Ajlan A, Pena J, Gershon M, Coffey G, Kunz PL, Li G, Recht LD (2015) Phase II pilot study of single-agent etirinotecan pegol (NKTR-102) in bevacizumab-resistant high grade glioma. J Neurooncol 123(2):277-282. doi:10.1007/s11060-015-1795-0

35. Robins HI, Zhang P, Gilbert MR, Chakravarti A, de Groot JF, Grimm SA, Wang F, Lieberman FS, Krauze A, Trotti AM, Mohile N, Kee AY, Colman H, Cavaliere R, Kesari S, Chmura SJ, Mehta M (2016) A randomized phase I/II study of ABT-888 in combination with temozolomide in recurrent temozolomide 
resistant glioblastoma: an NRG oncology RTOG group study. J Neurooncol 126(2):309-316. doi:10.1007/s11060-015-1966-Z

36. Chamberlain MC, Grimm S, Phuphanich S, Recht L, Zhu JZ, Kim L, Rosenfeld S, Fadul CE; Brain Tumor Investigational Consortium (2014) A phase 2 trial of verubulin for recurrent glioblastoma: a prospective study by the Brain Tumor Investigational Consortium (BTIC). J Neurooncol 118(2):335-343. doi:10.1007/s11060-014-1437-y

37. Jaeckle K, Schiff D, Anderson SK, Galanis E, Stella PJ, Flynn PJ, Sarkaria JN, Giannini C, Erickson BJ, Buckner JC (2013) NCCTG (Alliance) N0572: a phase II trial of sorafenib and temsirolimus in recurrent glioblastoma patients who progress following prior RT/temozolomide and VEGF inhibitors. J Clin Oncol 31(suppl) (abstract 2014)

38. Norden AD, Schiff D, Ahluwalia MS, Lesser GJ, Nayak L, Lee EQ, Rinne ML, Muzikansky A, Dietrich J, Purow B, Doherty LM, LaFrankie DC, Pulverenti JR, Rifenburg JA, Ruland SF, Smith KH, Gaffey SC, McCluskey C, Ligon KL, Reardon DA, Wen PY (2015) Phase II trial of triple-receptor tyrosine kinase receptor inhibitor nintedanib in recurrent high-grade gliomas. J Neurooncol 121(2):297-302. doi:10.1007/s11060-014-1631-y

39. Han SJ, Rolston JD, Molinaro AM, Clarke JL, Prados MD, Chang SM, Berger MS, DeSilva A, Butowski NA (2014) Phase II trial of 7 days on/7 days off temozolomide for recurrent high-grade glioma. Neuro Oncol 16(9):1255-1262. doi:10.1093/neuonc/ nou044

40. Muhic A, Poulsen HS, Sorensen M, Grunnet K, Lassen U (2013) Phase II open-label study of nintedanib in patients with recurrent glioblastoma multiforme. J Neurooncol 111(2):205-212. doi:10. 1007/s11060-012-1009-y

41. Kreisl TN, Smith P, Sul J, Salgado C, Iwamoto FM, Shih JH, Fine HA (2013) Continuous daily sunitinib for recurrent glioblastoma. J Neurooncol 111(1):41-48. doi:10.1007/s11060-012-0988-z

42. Omuro A, Chan TA, Abrey LE, Khasraw M, Reiner AS, Kaley TJ, Deangelis LM, Lassman AB, Nolan CP, Gavrilovic IT, Hormigo A, Salvant C, Heguy A, Kaufman A, Huse JT, Panageas
KS, Hottinger AF, Mellinghoff I (2013) Phase II trial of continuous low-dose temozolomide for patients with recurrent malignant glioma. Neuro Oncol 15(2):242-250. doi:10.1093/neuonc/ $\operatorname{nos} 295$

43. Friday BB, Anderson SK, Buckner J, Yu C, Giannini C, Geoffroy F, Schwerkoske J, Mazurczak M, Gross H, Pajon E, Jaeckle K, Galanis E (2012) Phase II trial of vorinostat in combination with bortezomib in recurrent glioblastoma: a north central cancer treatment group study. Neuro Oncol 14(2):215-221. doi:10.1093/ neuonc/nor198

44. Chamberlain MC, Johnston SK (2011) Salvage therapy with single agent bendamustine for recurrent glioblastoma. J Neurooncol 05(3):523-530. doi:10.1007/s11060-011-0612-7

45. Reardon DA, Desjardins A, Vredenburgh JJ, Gururangan S, Friedman AH, Herndon JE 2nd, Marcello J, Norfleet JA, McLendon RE, Sampson JH, Friedman HS (2011) Effect of CYP3A-inducing anti-epileptics on sorafenib exposure: results of a phase II study of sorafenib plus daily temozolomide in adults with recurrent glioblastoma. J Neurooncol 101(1):57-66. doi:10. 1007/s11060-010-0217-6

46. Wen PY, Schiff D, Cloughesy TF, Raizer JJ, Laterra J, Smitt M, Wolf M, Oliner KS, Anderson A, Zhu M, Loh E, Reardon DA (2011) A phase II study evaluating the efficacy and safety of AMG 102 (rilotumumab) in patients with recurrent glioblastoma. Neuro Oncol 13(4):437-446. doi:10.1093/neuonc/noq198

47. Reardon DA, Desjardins A, Vredenburgh JJ, Gururangan S, Friedman AH, Herndon JE 2nd, Marcello J, Norfleet JA, McLendon RE, Sampson JH, Friedman HS (2010) Phase 2 trial of erlotinib plus sirolimus in adults with recurrent glioblastoma. J Neurooncol 96(2):219-230. doi:10.1007/s11060-009-9950-0

48. Cortés J, Rugo HS, Twelves C, Awada A, Perez EA, Im SA, Zhao C, Hoch U, Tomkinson D, Buchanan J, Tagliaferri M, Hannah A, O'Shaughnessy J (2016) Safety and tolerability of etirinotecan pegol in advanced breast cancer: analysis of the randomized, phase 3 BEACON trial. Springerplus 5(1):1033. doi:10.1186/ s40064-016-2446-4 